\title{
Approximation results for split equilibrium problems and fixed point problems of nonexpansive semigroup in Hilbert spaces
}

\author{
Yasir Arfat ${ }^{1}$, Poom Kumam ${ }^{1,2,3^{*}}$, Parinya Sa Ngiamsunthorn ${ }^{4}$, Muhammad Aqeel Ahmad Khan ${ }^{5}$, \\ Hammad Sarwar ${ }^{5}$ and Hafiz Fukhar-ud-Din ${ }^{6}$
}

\author{
Correspondence: \\ poom.kumam@mail.kmutt.ac.th \\ 'KMUTTFixed Point Research \\ Laboratory, KMUTT-Fixed Point \\ Theory and Applications Research \\ Group, Department of Mathematics, \\ Faculity of Science, King Mongkut's \\ University of Technology Thonburi \\ (KMUTT), 126 Pracha-Uthit Road, \\ Bang Mod, Thrung Khru, 10140, \\ Bangkok, Thailand \\ ${ }^{2}$ Center of Excellence in Theoretical \\ and Computational Science \\ (TaCS-CoE), Science Laboratory \\ Building, King Mongkut's University \\ of Technology Thonburi (KMUTT), \\ 126 Pracha-Uthit Road,Band \\ Mod,Thrung Khru, 10140 Bangkok, \\ Thailand \\ Full list of author information is \\ available at the end of the article
}

\begin{abstract}
In this paper, we study a modified extragradient method for computing a common solution to the split equilibrium problem and fixed point problem of a nonexpansive semigroup in real Hilbert spaces. The weak and strong convergence characteristics of the proposed algorithm are investigated by employing suitable control conditions in such a setting of spaces. As a consequence, we provide a simplified analysis of various existing results concerning the extragradient method in the current literature. We also provide a numerical example to strengthen the theoretical results and the applicability of the proposed algorithm.
\end{abstract}

MSC: Primary 47H05; 47H09; 47J05; secondary 49H05

Keywords: Extragradient method; Split equilibrium problem; Fixed point problem; Nonexpansive semigroup; Weak and strong convergence

\section{Introduction}

The theory of nonlinear functional analysis, in particular fixed point theory, is a rich and thriving mathematical discipline. The theory of fixed points can be classified into theories of the existence of fixed points and approximation of fixed points, respectively. The branch metric fixed point theory is a beautiful interplay between the geometrical structures of the domain and the corresponding topological notions. It is evident that the celebrated Banach contraction principle paved the way for the development of metric fixed point theory as well as for modeling of various physical phenomena. On the other hand, the fixed point theory of nonexpansive mappings $(\|T x-T y\| \leq \| x-$ $y \|$, for all $x, y$ in a nonempty set $C$ ) is more restrictive than the corresponding contractions $(\|T x-T y\| \leq \alpha\|x-y\|$, for all $x, y$ in a nonempty set $C$ and $\alpha \in(0,1))$. However, the fixed point theory of nonexpansive mappings found valuable applications in convex feasibility problems, convex optimization problems, approximation theory, game theory, optimal transport theory, probability and statistics, information theory, signal and image processing and partial differential equations; see, for example, $[1,14,42]$ and the references cited therein.

(c) The Author(s) 2020. This article is licensed under a Creative Commons Attribution 4.0 International License, which permits use sharing, adaptation, distribution and reproduction in any medium or format, as long as you give appropriate credit to the original author(s) and the source, provide a link to the Creative Commons licence, and indicate if changes were made. The images or other third party material in this article are included in the article's Creative Commons licence, unless indicated otherwise in a credit line to the material. If material is not included in the article's Creative Commons licence and your intended use is not permitted by statutory regulation or exceeds the permitted use, you will need to obtain permission directly from the copyright holder. To view a copy of this licence, visit http://creativecommons.org/licenses/by/4.0/. 
It is remarked that the existence of solutions associated with the above-mentioned problems rely on the existence of fixed points of certain nonlinear mappings. Moreover, the existence of a common fixed point of a family of nonlinear mappings has relevant applications in applied mathematics. Let us recall that a family $\left\{T_{t}\right\}_{0 \leq t<\infty}$ of mappings defines a semigroup if $T(0) x=x$ and $T(a+b)=T(a) T(b)$. Such a family of mappings is closely related to first-order linear differential equations. Moreover, it corresponds to the theory of dynamical systems in such a way that the vector function space would define the state space, and the mappings $(t, x) \rightarrow T(t) x$ would represent the evolution function of a dynamical system. In this situation, the question of the existence of common fixed points can be interpreted as asking whether there exist points that are fixed during the state space transformation $T(t)$ at any given point of time $t$. Since the notion of semigroup has distinctive properties, it is natural to apply these results not only to deterministic dynamical systems but also to stochastic dynamical systems. The theory of nonexpansive semigroup has been widely studied to solve problems associated with the partial differential equation theory, evolutionary equation theory and fixed point theory; see, for example, [2, 28, 36, 39, 40] and the references cited therein. Moreover, the nonexpansive semigroup plays a central role in the study of abstract Cauchy problems [5, 7].

The equilibrium problem theory provides a systematic approach to studying a diverse range of problems arising in the field of physics, optimization, variational inequalities, transportation, economics, network and noncooperative games; see, for example, $[4,6,15,17]$ and the references cited therein. In 2012, Censor et al. [12] proposed a new theory of split variational inequality problem (SVIP). This theory aims to solve a pair of variational inequality problems in such a way that the solution of a variational inequality problem, under a given bounded linear operator, solves another variational inequality problem. Later on, Moudafi [32] generalized the concept of SVIP to that of split monotone variational inclusions (SMVIP) which includes, as a special case, SVIP, split common fixed point problem, split equilibrium problem and split feasibility problem. These problems have already been studied and successfully employed as a model in intensity-modulated radiation therapy treatment planning; see $[9,10]$. This formalism is also at the core of modeling of many inverse problems arising for phase retrieval and other real-world problems; for instance, in sensor networks in computerized tomography and data compression; see, for example, $[8,14]$. Another important application of SMVIP is to solve split Nash equilibrium problems associated with two related noncooperative strategic games [29].

It is worth mentioning that iterative construction for the common solution of equilibrium problem and fixed point problem is ubiquitous in the current theory of nonlinear functional analysis; see, for example, [11, 19-21, 23, 25, 26, 37, 43] and the references cited therein. In 2008, Plubtieng and Punpaeng [34] proposed an iterative algorithm which exhibits strong convergence towards the common fixed points of a nonexpansive semigroup. In 2010, Cianciaruso et al. [13] extended the results presented in [34] to find a common solution of equilibrium problem and fixed point problem associated with the nonexpansive semigroup; see also [24].

The class of proximal point algorithms (PPA), essentially due to Martinet [30], is prominent in variational inequality theory. The theory of PPA flourished with the seminal work of Rockafellar [35] and Moudafi [31], respectively. On the other hand, the class of extragradient algorithm, essentially due to Korpelevich [27], is well known in variational inequality theory. In 2006, Nadezhkina and Takahashi [33] introduced a hybrid extragradient al- 
gorithm for finding a common solution of fixed point problem and variational inequality problem in a real Hilbert space. In 2015, Thuy [41] proposed a hybrid extragradient method for equilibrium, variational inequality and fixed point problem of a nonexpansive semigroup in Hilbert spaces. In 2017, Dinh et al. [18] proposed two new extragradientproximal point algorithms for solving split equilibrium problem and fixed point problem of nonexpansive mappings in real Hilbert spaces.

Inspired and motivated by the ongoing research in this direction, we study a modified extragradient method for computing a common solution to the split equilibrium problem and fixed point problem of nonexpansive semigroup in real Hilbert spaces. The results concerning weak and strong convergence of the proposed algorithm are established by employing suitable conditions on the set of control sequences. The rest of the paper is organized as follows: In Sect. 2, we first define the necessary conventions to be adopted throughout the rest of the paper. We also define mathematical notions, concepts and necessary results in the form of lemmas as required in the sequel. Section 3 is devoted to weak convergence results whereas Sect. 4 comprises strong convergence results of the proposed modified extragradient methods in real Hilbert spaces. Section 5 provides a numerical example to strengthen the theoretical results presented in Sects. 3-4 as well as applicability of the proposed algorithm.

\section{Preliminaries}

This section is devoted to recalling some fundamental definitions, properties and notations concerned with the split equilibrium problem and fixed point problem in real Hilbert spaces. Throughout this paper, we write $x_{n} \rightarrow x\left(\right.$ resp. $\left.x_{n} \rightarrow x\right)$ to indicate the strong convergence (resp. the weak convergence) of a sequence $\left\{x_{n}\right\}_{n=1}^{\infty}$. Let $C$ be a nonempty subset of a real Hilbert space $H_{1}$ which is equipped with the inner product $\langle\cdot, \cdot\rangle$ and the induced norm $\|\cdot\|$. A family $\mathcal{T}=\{T(t): 0 \leq t<\infty\}$ of self-mappings defined on $C$ is called a one parameter strongly continuous nonexpansive semigroup (in short nonexpansive semigroup) if it satisfies the following conditions:

$$
\begin{aligned}
& \text { (i): } \quad T(0) x=\lim _{t \rightarrow 0} T(t) x=x, \quad \text { for all } x \in C ; \\
& \text { (ii): } \quad T(a+b)=T(a) T(b), \quad \text { for all } a, b \geq 0 ; \\
& \text { (iii): } \quad\|T(t) x-T(t) y\| \leq\|x-y\|, \quad \text { for all } x, y \in C \text { and } t \geq 0 ; \\
& \text { (iv) : for any } x \in C \text {, the mapping } t \mapsto T(t) x \text { is continuous. }
\end{aligned}
$$

We use $\operatorname{Fix}(\mathcal{T})$ to denote all the common fixed points of the family $\mathcal{T}$, that is,

$$
\operatorname{Fix}(\mathcal{T})=\{x \in C: x=T(t) x, 0 \leq t<\infty\}=\bigcap_{0 \leq t<\infty} \operatorname{Fix}(T(t))
$$

where $\operatorname{Fix}(T(t))$ is the set of fixed points of $T(t)$.

For a nonempty closed convex subset $C$ of a Hilbert space $H_{1}$, we define the metric projection operator $P_{C}: H_{1} \rightarrow C$ such that, for each $x \in H_{1}$, there exists a unique nearest point $P_{C} x \in C$ satisfying the following inequality:

$$
\left\|x-P_{C} x\right\| \leq\|x-y\| \quad \text { for all } y \in C .
$$


We remark that the metric projection operator $P_{C}$ satisfies nonexpansiveness in a Hilbert space and $\left\langle x-P_{C} x, P_{C} x-y\right\rangle \geq 0$ for all $x, y \in C$. Moreover, $P_{C}$ is a firmly nonexpansive mapping from $H_{1}$ onto $C$, that is,

$$
\left\|P_{C} x-P_{C} y\right\|^{2} \leq\left\langle x-y, P_{C} x-P_{C} y\right\rangle, \quad \text { for all } x, y \in C .
$$

Recall that a mapping $A$ is said to be:

(i) monotone if

$$
\langle A x-A y, x-y\rangle \geq 0, \quad \text { for all } x, y \in C
$$

(ii) $\lambda$-inverse strongly monotone if

$$
\langle x-y, A x-A y\rangle \geq \lambda\|A x-A y\|^{2}, \quad \text { for all } x, y \in C \text { and } \lambda>0 ;
$$

(iii) Lipschitz continuous if there exists a positive constant $L$ such that

$$
\|A x-A y\| \leq L\|x-y\|, \quad \text { for all } x, y \in C .
$$

Note that, if $A:=I-T$, where $I$ denotes the identity mapping, is a $\lambda$-inverse strongly monotone mapping, then:

(i) $A$ is $\left(\frac{1}{\lambda}\right)$-Lipschitz continuous mapping;

(ii) if $T$ is a nonexpansive mapping, then $A$ is $\left(\frac{1}{2}\right)$-inverse strongly monotone mapping;

(iii) if $\eta \in(0,2 \lambda]$, then $I-\eta A$ is a nonexpansive mapping.

The following lemma collects some well-known results in the context of a real Hilbert space.

Lemma 2.1 Let $H_{1}$ be a real Hilbert space, then:

(i) $\|x-y\|^{2}=\|x\|^{2}-\|y\|^{2}-2\langle x-y, y\rangle$, for all $x, y \in H_{1}$;

(ii) $\|x+y\|^{2} \leq\|x\|^{2}+2\langle y, x+y\rangle$, for all $x, y \in H_{1}$;

(iii) $2\langle x-y, u-v\rangle=\|x-v\|^{2}+\|y-u\|^{2}-\|x-u\|^{2}-\|y-v\|^{2}$, for all $x, y, u, v \in H_{1}$;

(iv) $\|\alpha x+(1-\alpha) y\|^{2}=\alpha\|x\|^{2}+(1-\alpha)\|y\|^{2}-\alpha(1-\alpha)\|x-y\|^{2}$ for all $x, y \in H_{1}$ and $\alpha \in \mathbb{R}$.

It is well known that $H_{1}$ satisfies Opial's condition, that is, for any sequence $\left\{x_{n}\right\}$ in $H_{1}$ with $x_{n} \rightarrow x$, the inequality

$$
\liminf _{n \rightarrow \infty}\left\|x_{n}-x\right\|<\liminf _{n \rightarrow \infty}\left\|x_{n}-y\right\|
$$

holds for all $y \in H_{1}$ with $x \neq y$.

Recall that a mapping $T: H_{1} \rightarrow H_{1}$ is said to be demiclosed at the origin if for any sequence $\left\{x_{n}\right\}$ in $H_{1}$ with $x_{n} \rightarrow x$ and $\left\|x_{n}-T x_{n}\right\| \rightarrow 0$, we have $x=T x$. We recall that the subdifferential of a function $f: C \rightarrow \mathbb{R}$ at $x$ is defined and denoted as

$$
\partial_{f}(x)=\{z \in C: f(y)-f(x) \geq\langle z, y-x\rangle \text {, for all } y \in C\} .
$$

We now define the concept of a split equilibrium and a fixed point problem in Hilbert spaces. We also list some of the useful results required in the sequel. 
Let $C$ be a nonempty subset of a real Hilbert space $H_{1}, Q$ be a nonempty subset of a real Hilbert space $H_{2}$ and let $A: H_{1} \rightarrow H_{2}$ be a bounded linear operator. Let $F: C \times C \rightarrow \mathbb{R}$ and $G: Q \times Q \rightarrow \mathbb{R}$ be two bifunctions and let $\mathcal{T}=\{T(t): 0 \leq t<\infty\}$ and $\mathcal{S}=\{S(s): 0 \leq s<\infty\}$ be two nonexpansive semigroups. Recall that a split equilibrium and fixed point problem (SEFPP) is to find

$$
x^{*} \in C \text { such that }\left\{\begin{array}{l}
F\left(x^{*}, x\right) \geq 0 \text { for all } x \in C, \\
x^{*} \in \operatorname{Fix}(\mathcal{T})
\end{array}\right.
$$

and

$$
y^{*}=A x^{*} \in Q \quad \text { such that }\left\{\begin{array}{l}
G\left(y^{*}, y\right) \geq 0 \text { for all } y \in Q, \\
y^{*} \in \operatorname{Fix}(\mathcal{S}) .
\end{array}\right.
$$

It is remarked that the problem addressed in the inequality (1) represents the classical equilibrium problem and fixed point problem of a nonexpansive semigroup. The solution set of an equilibrium problem is denoted as $\operatorname{EP}(C, F)$. Recall that a bifunction $F: C \times C \rightarrow$ $\mathbb{R}$ is said to be:

(i) strongly monotone with constant $\tau>0$ if

$$
F(x, y)+F(y, x) \leq-\tau\|x-y\|^{2}, \quad \text { for all } x, y \in C
$$

(ii) monotone if

$$
F(x, y)+F(y, x) \leq 0, \quad \text { for all } x, y \in C
$$

(iii) pseudomonotone if

$$
\text { for all } x, y \in C, \quad F(x, y) \geq 0 \quad \Longrightarrow \quad F(y, x) \leq 0 \text {; }
$$

(iv) pseudomonotone with respect to a nonempty subset $D$ of $C$ if

$$
\text { for all } x^{*} \in D \text { and for all } y \in C, \quad F\left(x^{*}, y\right) \geq 0 \quad \Longrightarrow \quad F\left(y, x^{*}\right) \leq 0 \text {; }
$$

(v) Lipschitz-type continuous if there exist positive constants $c_{1}$ and $c_{2}$ such that

$$
F(x, y)+F(y, x) \geq F(x, z)-c_{1}\|x-y\|^{2}-c_{2}\|y-z\|^{2}, \quad \text { for all } x, y, z \in C .
$$

Note that the implications (i) $\Longrightarrow$ (ii) $\Longrightarrow$ (iii) $\Longrightarrow$ (iv) are easy to follow. Moreover, if a mapping is Lipschitz continuous on $C$ then for any $\epsilon>0$ it is Lipschitz-type continuous on $C$ with $c_{1}=\frac{L}{2 \epsilon}$ and $c_{2}=\frac{L \epsilon}{2}$.

In order to solve monotone and pseudomonotone equilibrium problems, we assume that the bifunction $G: Q \times Q \rightarrow \mathbb{R}$ satisfies the following set of standard properties:

(A1) $G(u, u)=0$ for all $u \in Q$;

(A2) $G$ is monotone on $Q$; 
(A3) for each $v \in C$, the function $x \mapsto G(u, v)$ is upper hemicontinuous, that is, for each $u, w \in C$,

$$
\lim _{\lambda \rightarrow 0} G(\lambda w+(1-\lambda) u, v) \leq G(u, v)
$$

(A4) for each $u \in C$, the function $v \mapsto G(u, v)$ is convex and lower semi-continuous.

Moreover, the bifunction $F: C \times C \rightarrow \mathbb{R}$ satisfies the following set of standard properties:

(B1) $F(x, x)=0$ for all $x \in C$;

(B2) $F$ is pseudomonotone on $C$ with respect to $\operatorname{EP}(C, F)$;

(B3) $F$ is weakly continues on $C \times C$;

(B4) for each $x \in C$, the function $y \mapsto F(x, y)$ is convex and subdifferentiable;

(B5) $F$ is Lipschitz-type continuous on $C$.

Lemma $2.2([6,15])$ Let $Q$ be a nonempty closed convex subset of a real Hilbert space $\mathrm{H}_{2}$ and let $\mathrm{G}: \mathrm{Q} \times \mathrm{Q} \rightarrow \mathbb{R}$ be a bifunction satisfying conditions (A1)-(A4). For $s>0$ and $u \in H_{2}$, there exists $w \in C$ such that

$$
G(w, v)+\frac{1}{s}\langle v-w, w-u\rangle \geq 0, \quad \text { for all } v \in C
$$

Moreover, define a mapping $S_{s}^{G}: H_{2} \rightarrow Q$ by

$$
S_{s}^{G}(u)=\left\{w \in Q: G(w, v)+\frac{1}{s}\langle v-w, w-u\rangle \geq 0, \text { for all } v \in C\right\},
$$

for all $u \in H_{2}$. Then the following hold:

(i) $S_{s}^{G}(u)$ is single-valued;

(ii) $S_{s}^{G}(u)$ is firmly nonexpansive, i.e., for every $x, y \in \mathrm{H}_{2}$,

$$
\left\|S_{s}^{G}(u)-S_{s}^{G}(v)\right\|^{2} \leq\left\langle S_{s}^{G}(u)-S_{s}^{G}(v), u-v\right\rangle
$$

(iii) $\operatorname{Fix}\left(S_{s}^{G}\right)=\operatorname{EP}(Q, G)$;

(iv) $\operatorname{EP}(Q, G)$ is closed and convex.

Lemma 2.3 ([20]) Let $Q$ be a nonempty closed convex subset of a real Hilbert space $\mathrm{H}_{2}$ and let $S_{s}^{G}(u)$ be the same as in Lemma 2.2. For $a, b>0$ and $u, v \in H_{2}$, we have

$$
\left\|S_{a}^{G}(u)-S_{b}^{G}(v)\right\| \leq\|u-v\|+\frac{|b-a|}{b}\left\|S_{b}^{G}(v)-v\right\| .
$$

Lemma 2.4 ([38]) Let $C$ be a nonempty bounded closed and convex subset of a real Hilbert space $H_{1}$. Let $\mathcal{T}=\{T(t): 0 \leq t<\infty\}$ be a nonexpansive semigroup on $C$; then, for all $u \geq 0$,

$$
\lim _{t \rightarrow \infty} \sup _{x \in C}\left\|\frac{1}{t} \int_{0}^{t} T(s) x d s-T(u)\left(\frac{1}{t} \int_{0}^{t} T(s) x d s\right)\right\|=0 .
$$




\section{Weak convergence results}

We start our main result of this section with the introduction of the proposed modified extragradient method in real Hilbert spaces as follows.

Algorithm 3.1 Let $C \subseteq H_{1}$ and $Q \subseteq H_{2}$ be nonempty subsets of real Hilbert spaces $H_{1}$ and $H_{2}$, respectively. Let $A: H_{1} \rightarrow H_{2}$ be a bounded linear operator and $A^{*}$ be its adjoint. Let $F: C \times C \rightarrow \mathbb{R}$ and $G: Q \times Q \rightarrow \mathbb{R}$ be two bifunctions satisfying conditions (B1)-(B5) and (A1)-(A4), respectively. Let $\mathcal{T}=\{T(t): 0 \leq t<\infty\}$ and $\mathcal{S}=\{S(s): 0 \leq s<\infty\}$ be two nonexpansive semigroups. Let $\Gamma=\left\{x^{*} \in C: x^{*} \in \operatorname{EP}(C, F) \cap \operatorname{Fix}(\mathcal{T})\right.$ and $A x^{*} \in \operatorname{EP}(Q, G) \cap$ $\operatorname{Fix}(\mathcal{S})\} \neq \emptyset$, then we have

$$
\begin{aligned}
& x_{1} \in C_{1}=C, \\
& y_{n}=\arg \min \left\{\lambda_{n} F\left(x_{n}, y\right)+\frac{1}{2}\left\|y-x_{n}\right\|^{2}: y \in C\right\}, \\
& z_{n}=\arg \min \left\{\lambda_{n} F\left(y_{n}, z\right)+\frac{1}{2}\left\|z-x_{n}\right\|^{2}: z \in C\right\}, \\
& v_{n}=\left(1-\alpha_{n}\right) z_{n}+\alpha_{n} \frac{1}{t_{n}} \int_{0}^{t_{n}} T(t) z_{n} d t, \\
& u_{n}=T_{r_{n}}^{G} A v_{n}, \\
& x_{n+1}=P_{C}\left(v_{n}+\xi A^{*}\left(\frac{1}{s_{n}} \int_{0}^{s_{n}} S(s) u_{n} d s-A v_{n}\right)\right) .
\end{aligned}
$$

The following result establishes a crucial relation among the sequences $\left\{x_{n}\right\},\left\{y_{n}\right\}$ and $\left\{z_{n}\right\}$ for the convergence analysis of Algorithm 3.1.

Lemma 3.1 ([3]) Suppose that $x^{*} \in \mathrm{EP}(C, F), F$ is pseudomonotone on $C$ and $F(x, \cdot)$ is convex and subdifferentiable on $C$ for all $x \in C$, then we have

(i) $\lambda_{n}\left\{F\left(x_{n}, y\right)-F\left(x_{n}, y_{n}\right)\right\} \geq\left\langle y_{n}-x_{n}, y_{n}-y\right\rangle$, for all $y \in C$;

(ii) $\left\|z_{n}-x^{*}\right\|^{2} \leq\left\|x_{n}-x^{*}\right\|^{2}-\left(1-2 \lambda_{n} c_{2}\right)\left\|z_{n}-y_{n}\right\|^{2}-\left(1-2 \lambda_{n} c_{1}\right)\left\|x_{n}-y_{n}\right\|^{2}$, for all $n \geq 0$.

Theorem 3.1 Let $C \subseteq H_{1}, Q \subseteq H_{2}, A, F, G, \mathcal{T}$ and $\mathcal{S}$ be as in Algorithm 3.1. Assume that the following set of control conditions are satisfied:

(C1) $\left\{\lambda_{n}\right\} \subset[a, b]$ for some $a, b \in\left(0, \min \left\{\frac{1}{2 c_{1}}, \frac{1}{2 c_{2}}\right\}\right)$;

(C2) $0 \leq d<e \leq \alpha_{n} \leq f<1, \liminf _{n \rightarrow \infty} r_{n}>0, \lim _{n \rightarrow 0} t_{n}=0=\lim _{n \rightarrow 0} s_{n}$;

(C3) $0<\xi<\frac{1}{\|A\|^{2}}$.

If $\Gamma \neq \emptyset$ then the sequences $\left\{x_{n}\right\},\left\{y_{n}\right\}$ and $\left\{z_{n}\right\}$ defined by Algorithm 3.1 converge weakly to a point in $\Gamma$.

Proof For simplicity, we divide the proof into the following four steps:

Step 1. $\lim _{n \rightarrow \infty}\left\|x_{n}-x^{*}\right\|$ exists for all $x^{*} \in \Gamma$.

It follows from Algorithm 3.1 that

$$
\begin{aligned}
\left\|v_{n}-x^{*}\right\| & =\left\|\left(1-\alpha_{n}\right) z_{n}+\alpha_{n} \frac{1}{t_{n}} \int_{0}^{t_{n}} T(t) z_{n} d t-x^{*}\right\| \\
& \leq\left(1-\alpha_{n}\right)\left\|z_{n}-x^{*}\right\|+\alpha_{n}\left\|\frac{1}{t_{n}} \int_{0}^{t_{n}} T(t) z_{n} d t-T(t) x^{*}\right\|
\end{aligned}
$$




$$
\begin{aligned}
& \leq\left(1-\alpha_{n}\right)\left\|z_{n}-x^{*}\right\|+\alpha_{n}\left\|z_{n}-x^{*}\right\| \\
& =\left\|z_{n}-x^{*}\right\| .
\end{aligned}
$$

Moreover, from (C1) and Lemma 3.1(ii), we have

$$
\begin{aligned}
\left\|z_{n}-x^{*}\right\|^{2} & \leq\left\|x_{n}-x^{*}\right\|^{2}-\left(1-2 \lambda_{n} c_{2}\right)\left\|z_{n}-y_{n}\right\|^{2}-\left(1-2 \lambda_{n} c_{1}\right)\left\|x_{n}-y_{n}\right\|^{2} \\
& \leq\left\|x_{n}-x^{*}\right\|^{2} .
\end{aligned}
$$

Using (4), the estimate (3) implies that

$$
\left\|v_{n}-x^{*}\right\| \leq\left\|x_{n}-x^{*}\right\|
$$

We now estimate

$$
\begin{aligned}
\left\|x_{n+1}-x^{*}\right\|^{2}= & \left\|P_{C}\left(v_{n}+\xi A^{*}\left(\frac{1}{s_{n}} \int_{0}^{s_{n}} S(s) u_{n} d s-A v_{n}\right)\right)-P_{C}\left(x^{*}\right)\right\|^{2} \\
\leq & \left\|\left(v_{n}-x^{*}\right)+\xi A^{*}\left(\frac{1}{s_{n}} \int_{0}^{s_{n}} S(s) u_{n} d s-A v_{n}\right)\right\|^{2} \\
= & \left\|v_{n}-x^{*}\right\|^{2}+\left\|\xi A^{*}\left(\frac{1}{s_{n}} \int_{0}^{s_{n}} S(s) u_{n} d s-A v_{n}\right)\right\|^{2} \\
& +2 \xi\left\langle v_{n}-x^{*}, A^{*}\left(\frac{1}{s_{n}} \int_{0}^{s_{n}} S(s) u_{n} d s-A v_{n}\right)\right\rangle \\
\leq & \left\|v_{n}-x^{*}\right\|^{2}+\xi^{2}\left\|A^{*}\right\|^{2} \sigma_{n}^{2} \\
& +2 \xi\left\langle A v_{n}-A x^{*}, \frac{1}{s_{n}} \int_{0}^{s_{n}} S(s) u_{n} d s-A v_{n}\right\rangle
\end{aligned}
$$

where $\sigma_{n}=\left\|\frac{1}{s_{n}} \int_{0}^{s_{n}} S(s) u_{n} d s-A v_{n}\right\|$.

On the other hand

$$
\begin{aligned}
&\left\langle A v_{n}-A x^{*}, \frac{1}{s_{n}} \int_{0}^{s_{n}} S(s) u_{n} d s-A v_{n}\right\rangle \\
&=\left\langle\left(\frac{1}{s_{n}} \int_{0}^{s_{n}} S(s) u_{n} d s-A x^{*}\right)-\left(\frac{1}{s_{n}} \int_{0}^{s_{n}} S(s) u_{n} d s-A v_{n}\right), \frac{1}{s_{n}} \int_{0}^{s_{n}} S(s) u_{n} d s-A v_{n}\right\rangle \\
&=\left\langle\frac{1}{s_{n}} \int_{0}^{s_{n}} S(s) u_{n} d s-A x^{*}, \frac{1}{s_{n}} \int_{0}^{s_{n}} S(s) u_{n} d s-A v_{n}\right\rangle-\left\|\frac{1}{s_{n}} \int_{0}^{s_{n}} S(s) u_{n} d s-A v_{n}\right\|^{2} \\
&=\frac{1}{2}\left(\left\|\frac{1}{s_{n}} \int_{0}^{s_{n}} S(s) u_{n} d s-A x^{*}\right\|^{2}+\left\|\frac{1}{s_{n}} \int_{0}^{s_{n}} S(s) u_{n} d s-A v_{n}\right\|^{2}-\left\|A v_{n}-A x^{*}\right\|^{2}\right) \\
& \quad-\left\|\frac{1}{s_{n}} \int_{0}^{s_{n}} S(s) u_{n} d s-A v_{n}\right\|^{2} \\
&=\frac{1}{2}\left(\left\|\frac{1}{s_{n}} \int_{0}^{s_{n}} S(s) u_{n} d s-A x^{*}\right\|^{2}-\left\|A v_{n}-A x^{*}\right\|^{2}\right)-\frac{1}{2}\left\|\frac{1}{s_{n}} \int_{0}^{s_{n}} S(s) u_{n} d s-A v_{n}\right\|^{2} \\
& \leq \frac{1}{2}\left(\left\|u_{n}-A x^{*}\right\|^{2}-\left\|A v_{n}-A x^{*}\right\|^{2}\right)-\frac{1}{2} \sigma_{n}^{2} .
\end{aligned}
$$


Note that

$$
\begin{aligned}
\left\|u_{n}-A x^{*}\right\|^{2} & =\left\|T_{r_{n}}^{G} A v_{n}-A x^{*}\right\|^{2} \leq\left\langle T_{r_{n}}^{G} A v_{n}-T_{r_{n}}^{G} A x^{*}, A v_{n}-A x^{*}\right\rangle \\
& =\frac{1}{2}\left(\left\|T_{r_{n}}^{G} A v_{n}-T_{r_{n}}^{G} A x^{*}\right\|^{2}+\left\|A v_{n}-A x^{*}\right\|^{2}-\left\|T_{r_{n}}^{G} A v_{n}-A v_{n}\right\|^{2}\right) \\
& =\left\|A v_{n}-A x^{*}\right\|^{2}-\left\|u_{n}-A v_{n}\right\|^{2} .
\end{aligned}
$$

Using (8), the estimate (7) implies that

$$
\left\langle A v_{n}-A x^{*}, \frac{1}{s_{n}} \int_{0}^{s_{n}} S(s) u_{n} d s-A v_{n}\right\rangle \leq \frac{-1}{2}\left(\left\|u_{n}-A v_{n}\right\|^{2}+\sigma_{n}^{2}\right) .
$$

It follows from (6) and (9) that

$$
\left\|x_{n+1}-x^{*}\right\|^{2} \leq\left\|v_{n}-x^{*}\right\|^{2}-\xi\left(1-\xi\left\|A^{*}\right\|^{2}\right) \sigma_{n}^{2}-\xi\left\|u_{n}-A v_{n}\right\|^{2} .
$$

Utilizing (C3), the estimate (10) implies that

$$
\left\|x_{n+1}-x^{*}\right\| \leq\left\|v_{n}-x^{*}\right\| .
$$

Combining (5) and (11), we have

$$
\left\|x_{n+1}-x^{*}\right\| \leq\left\|x_{n}-x^{*}\right\| .
$$

Applying induction on (12), we conclude that the sequence $\left\{x_{n}-x^{*}\right\}_{n=1}^{\infty}$ is bounded and hence $\lim _{n \rightarrow \infty}\left\|x_{n}-x^{*}\right\|$ exists.

Step 2. Show that:

(i) $\lim _{n \rightarrow \infty}\left\|x_{n}-x^{*}\right\|=\lim _{n \rightarrow \infty}\left\|v_{n}-x^{*}\right\|=\lim _{n \rightarrow \infty}\left\|z_{n}-x^{*}\right\|$;

(ii) $\lim _{n \rightarrow \infty}\left\|u_{n}-A v_{n}\right\|=0$;

(iii) $\lim _{n \rightarrow \infty}\left\|u_{n}-S(t) u_{n}\right\|=0=\lim _{n \rightarrow \infty}\left\|z_{n}-T(s) z_{n}\right\|$.

Since $\lim _{n \rightarrow \infty}\left\|x_{n}-x^{*}\right\|$ exists, therefore it follows from the estimates (4) and (5) that

$$
\lim _{n \rightarrow \infty}\left\|x_{n}-x^{*}\right\|=\lim _{n \rightarrow \infty}\left\|v_{n}-x^{*}\right\|=\lim _{n \rightarrow \infty}\left\|z_{n}-x^{*}\right\| .
$$

Note that the estimate (10) implies that

$$
\xi\left(1-\xi\left\|A^{*}\right\|^{2}\right) \sigma_{n}^{2}+\xi\left\|u_{n}-A v_{n}\right\|^{2} \leq\left\|x_{n}-x^{*}\right\|^{2}-\left\|x_{n+1}-x^{*}\right\|^{2} .
$$

Letting $n \rightarrow \infty$ in the above estimate, we have

$$
\lim _{n \rightarrow \infty}\left\|\frac{1}{s_{n}} \int_{0}^{s_{n}} S(s) u_{n} d s-A v_{n}\right\|=0=\lim _{n \rightarrow \infty}\left\|u_{n}-A v_{n}\right\| .
$$

Utilizing (13) and the following triangular identity:

$$
\left\|\frac{1}{s_{n}} \int_{0}^{s_{n}} S(s) u_{n} d s-u_{n}\right\| \leq\left\|\frac{1}{s_{n}} \int_{0}^{s_{n}} S(s) u_{n} d s-A v_{n}\right\|+\left\|A v_{n}-u_{n}\right\|,
$$


we have

$$
\lim _{n \rightarrow \infty}\left\|\frac{1}{s_{n}} \int_{0}^{s_{n}} S(s) u_{n} d s-u_{n}\right\|=0 .
$$

Observe that

$$
\begin{aligned}
\left\|u_{n}-S(t) u_{n}\right\| \leq & \left\|u_{n}-\frac{1}{s_{n}} \int_{0}^{s_{n}} S(t) u_{n} d s\right\|+\left\|\frac{1}{s_{n}} \int_{0}^{s_{n}} S(s) u_{n} d s-S(t) \frac{1}{s_{n}} \int_{0}^{s_{n}} S(s) u_{n} d s\right\| \\
& +\left\|S(t) \frac{1}{s_{n}} \int_{0}^{s_{n}} S(s) u_{n} d s-u_{n}\right\| \\
\leq & 2\left\|u_{n}-\frac{1}{s_{n}} \int_{0}^{s_{n}} S(s) u_{n} d s\right\|+\left\|\frac{1}{s_{n}} \int_{0}^{s_{n}} S(s) u_{n} d s-S(t) \frac{1}{s_{n}} \int_{0}^{s_{n}} S(s) u_{n} d s\right\| .
\end{aligned}
$$

It now follows from (14) and Lemma 2.4 that

$$
\lim _{n \rightarrow \infty}\left\|u_{n}-S(t) u_{n}\right\|=0
$$

In view of $(\mathrm{C} 1)$, consider the rearrangement of the estimate (4)

$$
\left(1-2 b c_{2}\right)\left\|z_{n}-y_{n}\right\|^{2}+\left(1-2 b c_{1}\right)\left\|x_{n}-y_{n}\right\|^{2} \leq\left\|x_{n}-x^{*}\right\|^{2}-\left\|z_{n}-x^{*}\right\|^{2} .
$$

Again, letting $n \rightarrow \infty$ in the above estimate, we have

$$
\lim _{n \rightarrow \infty}\left\|z_{n}-y_{n}\right\|=0=\lim _{n \rightarrow \infty}\left\|x_{n}-y_{n}\right\|
$$

Note that $\left\|z_{n}-x_{n}\right\| \leq\left\|z_{n}-y_{n}\right\|+\left\|y_{n}-x_{n}\right\|$, therefore letting $n \rightarrow \infty$ and utilizing (16) we get

$$
\lim _{n \rightarrow \infty}\left\|z_{n}-x_{n}\right\|=0
$$

Utilizing Lemma 2.1(iv), we now estimate

$$
\begin{aligned}
\left\|v_{n}-x^{*}\right\|^{2}= & \left\|\left(1-\alpha_{n}\right) z_{n}+\alpha_{n} \frac{1}{t_{n}} \int_{0}^{t_{n}} T(t) z_{n} d t-x^{*}\right\|^{2} \\
= & \left\|\left(1-\alpha_{n}\right)\right\| z_{n}-x^{*}\left\|+\alpha_{n} \frac{1}{t_{n}} \int_{0}^{t_{n}} T(t) z_{n} d t-T(t) x^{*}\right\|^{2} \\
= & \left(1-\alpha_{n}\right)\left\|z_{n}-x^{*}\right\|^{2}+\alpha_{n}\left\|\frac{1}{t_{n}} \int_{0}^{t_{n}} T(t) z_{n} d t-T(t) x^{*}\right\|^{2} \\
& -\alpha_{n}\left(1-\alpha_{n}\right)\left\|\frac{1}{t_{n}} \int_{0}^{t_{n}} T(t) z_{n} d t-z_{n}\right\| \\
\leq & \left\|z_{n}-x^{*}\right\|^{2}-\alpha_{n}\left(1-\alpha_{n}\right)\left\|\frac{1}{t_{n}} \int_{0}^{t_{n}} T(t) z_{n} d t-z_{n}\right\| .
\end{aligned}
$$

In view of (C2), consider the following rearrangement of the above estimate:

$$
e(1-f)\left\|\frac{1}{t_{n}} \int_{0}^{t_{n}} T(t) z_{n} d t-z_{n}\right\| \leq\left\|z_{n}-x^{*}\right\|^{2}-\left\|v_{n}-x^{*}\right\|^{2} .
$$


Again, letting $n \rightarrow \infty$ in the above estimate, we have

$$
\lim _{n \rightarrow \infty}\left\|\frac{1}{t_{n}} \int_{0}^{t_{n}} T(t) z_{n} d t-z_{n}\right\|=0 .
$$

In a similar fashion, utilizing (18) and Lemma 2.4, we get

$$
\lim _{n \rightarrow \infty}\left\|z_{n}-T(s) z_{n}\right\|=0
$$

Now, observe that

$$
\begin{aligned}
\left\|v_{n}-x_{n}\right\| & \leq\left\|v_{n}-z_{n}\right\|+\left\|z_{n}-x_{n}\right\| \\
& =\alpha_{n}\left\|\frac{1}{t_{n}} \int_{0}^{t_{n}} T(t) z_{n} d t-z_{n}\right\|+\left\|z_{n}-x_{n}\right\| \\
& \leq f\left\|\frac{1}{t_{n}} \int_{0}^{t_{n}} T(t) z_{n} d t-z_{n}\right\|+\left\|z_{n}-x_{n}\right\| .
\end{aligned}
$$

Utilizing (17) and (18), the above estimate implies that

$$
\lim _{n \rightarrow \infty}\left\|v_{n}-x_{n}\right\|=0
$$

Step 3 . The sequences $\left\{x_{n}\right\}$ and $\left\{z_{n}\right\}$ converge weakly to $p$ and $\left\{u_{n}\right\}$ converges weakly to $A p$.

It follows from Step 1 that $\lim _{n \rightarrow \infty}\left\|x_{n}-x^{*}\right\|$ exists. Moreover, it follows from the boundedness of the sequence $\left\{x_{n}\right\}$ that there exists a subsequence $\left\{x_{n_{j}}\right\}$ of $\left\{x_{n}\right\}$ such that $x_{n_{j}} \rightarrow p$ as $j \rightarrow \infty$. The estimate (20) then implies that $v_{n_{j}} \rightarrow p$ and $A v_{n_{j}} \rightarrow A p$ as $j \rightarrow \infty$. Moreover, the estimate (13) then implies that $u_{n_{j}} \rightarrow A p$ as $j \rightarrow \infty$. Furthermore, the estimate (17) then implies that $z_{n_{j}} \rightarrow p$ as $j \rightarrow \infty$. Assume that if $p \notin \operatorname{Fix}(\mathcal{T})$ then $p \neq T(s) p$ for some $s \in[0, \infty)$. Now utilizing the nonexpansivity of $T(s)$, the estimate (19) and the Opial property, we get

$$
\begin{aligned}
\liminf _{j \rightarrow \infty}\left\|z_{n_{j}}-p\right\| & <\liminf _{j \rightarrow \infty}\left\|z_{n_{j}}-T(s) p\right\| \\
& \leq \liminf _{j \rightarrow \infty}\left\|z_{n_{j}}-T(s) z_{n_{j}}\right\|+\liminf _{j \rightarrow \infty}\left\|T(s) z_{n_{j}}-T(s) p\right\| \\
& =\liminf _{j \rightarrow \infty}\left\|z_{n_{j}}-p\right\|,
\end{aligned}
$$

a contradiction. Hence $p \in \operatorname{Fix}(\mathcal{T})$. Moreover, from Lemma 3.1(i) we get $p \in \operatorname{EP}(C, F)$ and hence $p \in \operatorname{EP}(C, F) \cap \operatorname{Fix}(\mathcal{T})$. On the other hand, assume to the contrary that $A p \notin \operatorname{Fix}(\mathcal{S})$ then $A p \neq S(t) A p$ for some $t \in[0, \infty)$. Now utilizing the nonexpansivity of $S(t)$, the estimate (15) and the Opial property, we get

$$
\begin{aligned}
\liminf _{j \rightarrow \infty}\left\|u_{n_{j}}-A p\right\| & <\liminf _{j \rightarrow \infty}\left\|u_{n_{j}}-S(t) A p\right\| \\
& \leq \liminf _{j \rightarrow \infty}\left\|u_{n_{j}}-S(t) u_{n_{j}}\right\|+\liminf _{j \rightarrow \infty}\left\|S(t) u_{n_{j}}-S(t) A p\right\| \\
& =\liminf _{j \rightarrow \infty}\left\|u_{n_{j}}-A p\right\|,
\end{aligned}
$$


a contradiction. Hence $A p \in \operatorname{Fix}(\mathcal{S})$. Note that $\operatorname{Fix}\left(T_{r_{n}}^{G}\right)=\operatorname{EP}(Q, G)$. Again, contradicting the fact that $T_{r_{n}}^{G} A p \neq A p$, then utilizing the estimate (13), the Opial property and Lemma 2.3, we get

$$
\begin{aligned}
\liminf _{j \rightarrow \infty}\left\|A v_{n_{j}}-A p\right\| & <\liminf _{j \rightarrow \infty}\left\|A v_{n_{j}}-T_{r_{n}}^{G} A p\right\| \\
& \leq \liminf _{j \rightarrow \infty}\left\|A v_{n_{j}}-u_{n_{j}}\right\|+\liminf _{j \rightarrow \infty}\left\|u_{n_{j}}-T_{r_{n}}^{G} A p\right\| \\
& =\liminf _{j \rightarrow \infty}\left\|T_{r_{n_{j}}}^{G} A v_{n_{j}}-T_{r_{n}}^{G} A p\right\| \\
& \leq \liminf _{j \rightarrow \infty}\left\|A v_{n_{j}}-A p\right\|+\frac{r_{n_{j}}-r_{n}}{r_{n_{j}}}\left\|A v_{n_{j}}-u_{n_{j}}\right\| \\
& =\liminf _{j \rightarrow \infty}\left\|A v_{n_{j}}-A p\right\|,
\end{aligned}
$$

a contradiction. This implies that $T_{r_{n}}^{G} A p=A p$ and hence $A p \in \operatorname{EP}(Q, G) \cap \operatorname{Fix}(\mathcal{S})$. This proves that $p \in \Gamma$. It remains to show that the sequence $\left\{x_{n}\right\}$ converges weakly to $p$ and $\left\{u_{n}\right\}$ converges weakly to $A p$. Assume contrary that there exists a subsequence $\left\{x_{n_{j}}\right\}$ of $\left\{x_{n}\right\}$ such that $x_{n_{j}} \rightarrow q$ as $j \rightarrow \infty$ where $q \in \Gamma$ such that $q \neq p$. Again, utilizing the Opial property, we get

$$
\begin{aligned}
\liminf _{j \rightarrow \infty}\left\|x_{n_{j}}-q\right\| & <\liminf _{j \rightarrow \infty}\left\|x_{n_{j}}-p\right\| \\
& =\liminf _{k \rightarrow \infty}\left\|x_{n_{k}}-p\right\| \\
& <\liminf _{k \rightarrow \infty}\left\|x_{n_{k}}-q\right\| \\
& =\liminf _{j \rightarrow \infty}\left\|x_{n_{j}}-q\right\|,
\end{aligned}
$$

a contradiction. This implies that $x_{n} \rightarrow p$ as $n \rightarrow \infty$. Moreover, from the estimates (16) and (17), we conclude that $z_{n} \rightarrow p$ and $v_{n} \rightarrow p$ as $n \rightarrow \infty$. Since $A v_{n} \rightarrow A p$ as $n \rightarrow \infty$, therefore from the estimate (13) we conclude that $u_{n} \rightarrow A p$ as $n \rightarrow \infty$. This completes the proof.

Corollary 3.1 ([18]) Let $C \subseteq H_{1}, Q \subseteq H_{2}, A, F$ and $G$ be as in Algorithm 3.1 and let $T$ and $S$ be two nonexpansive mappings. Assume that the following set of control conditions are satisfied:

(C1) $\left\{\lambda_{n}\right\} \subset[a, b]$ for some $a, b \in\left(0, \min \left\{\frac{1}{2 c_{1}}, \frac{1}{2 c_{2}}\right\}\right)$;

(C2) $0 \leq d<e \leq \alpha_{n} \leq f<1, \liminf _{n \rightarrow \infty} r_{n}>0$;

(C3) $0<\xi<\frac{1}{\|A\|^{2}}$.

If $\Gamma \neq \emptyset$ then the sequences $\left\{x_{n}\right\},\left\{y_{n}\right\}$ and $\left\{z_{n}\right\}$ defined by Algorithm 3.1 converge weakly to a point in $\Gamma$.

In order to solve the classical equilibrium problem together with the fixed point problem of nonexpansive semigroup, we prove the following result.

Theorem 3.2 Let $C \subseteq H_{1}, Q \subseteq H_{2}, A, F, G, \mathcal{T}$ and $\mathcal{S}$ be as in Algorithm 3.1. Assume that the following set of control conditions are satisfied:

(C1) $\left\{\lambda_{n}\right\} \subset[a, b]$ for some $a, b \in\left(0, \min \left\{\frac{1}{2 c_{1}}, \frac{1}{2 c_{2}}\right\}\right)$; 
(C2) $0 \leq d<e \leq \alpha_{n} \leq f<1, \liminf _{n \rightarrow \infty} r_{n}>0, \lim _{n \rightarrow 0} t_{n}=0=\lim _{n \rightarrow 0} s_{n}$;

(C3) $0<\xi<\frac{1}{\|A\|^{2}}$.

If $\Gamma \neq \emptyset$ then the sequences $\left\{x_{n}\right\},\left\{y_{n}\right\}$ and $\left\{z_{n}\right\}$ defined by Algorithm 3.1 converge weakly to a point in $\Gamma$.

Proof Set $H_{1}=H_{2}, C=Q$ and $A=I$ (the identity mapping) then the desired result follows from Theorem 3.1 immediately.

Similarly, the following result addresses the classical equilibrium problem together with the fixed point problem of nonexpansive mapping.

Corollary 3.2 Let $C \subseteq H_{1}, Q \subseteq H_{2}, A, F$ and $G$ be as in Algorithm 3.1 and let $T$ and $S$ be two nonexpansive mappings. Assume that the following set of control conditions are satisfied:

(C1) $\left\{\lambda_{n}\right\} \subset[a, b]$ for some $a, b \in\left(0, \min \left\{\frac{1}{2 c_{1}}, \frac{1}{2 c_{2}}\right\}\right)$;

(C2) $0 \leq d<e \leq \alpha_{n} \leq f<1, \liminf _{n \rightarrow \infty} r_{n}>0$;

(C3) $0<\xi<\frac{1}{\|A\|^{2}}$.

If $\Gamma \neq \emptyset$ then the sequences $\left\{x_{n}\right\},\left\{y_{n}\right\}$ and $\left\{z_{n}\right\}$ defined by Algorithm 3.1 converge weakly to a point in $\Gamma$.

\section{Strong convergence results}

In this section, we combine the proposed modified extragradient method together with the classical shrinking projection algorithm to establish the strong convergence results. Our algorithm reads as follows.

Algorithm 4.1 Let $C \subseteq H_{1}$ and $Q \subseteq H_{2}$ be nonempty subsets of real Hilbert spaces $H_{1}$ and $H_{2}$, respectively. Let $A: H_{1} \rightarrow H_{2}$ be a bounded linear operator and $A^{*}$ be its adjoint. Let $F: C \times C \rightarrow \mathbb{R}$ and $G: Q \times Q \rightarrow \mathbb{R}$ be two bifunctions satisfying conditions (B1)-(B5) and (A1)-(A4), respectively. Let $\mathcal{T}=\{T(t): 0 \leq t<\infty\}$ and $\mathcal{S}=\{S(s): 0 \leq s<\infty\}$ be two nonexpansive semigroups. Let $\Gamma=\left\{x^{*} \in C: x^{*} \in \operatorname{EP}(C, F) \cap \operatorname{Fix}(\mathcal{T})\right.$ and $A x^{*} \in \operatorname{EP}(Q, G) \cap$ $\operatorname{Fix}(\mathcal{S})\} \neq \emptyset$, then we have

$$
\begin{aligned}
& x_{1} \in C_{1}=C, \\
& y_{n}=\arg \min \left\{\lambda_{n} F\left(x_{n}, y\right)+\frac{1}{2}\left\|y-x_{n}\right\|^{2}: y \in C\right\}, \\
& z_{n}=\arg \min \left\{\lambda_{n} F\left(y_{n}, z\right)+\frac{1}{2}\left\|z-x_{n}\right\|^{2}: z \in C\right\}, \\
& v_{n}=\left(1-\alpha_{n}\right) z_{n}+\alpha_{n} \frac{1}{t_{n}} \int_{0}^{t_{n}} T(t) z_{n} d t, \\
& u_{n}=T_{r_{n}}^{G} A v_{n}, \\
& w_{n}=P_{C}\left(v_{n}+\xi A^{*}\left(\frac{1}{s_{n}} \int_{0}^{s_{n}} S(s) u_{n} d s-A v_{n}\right)\right), \\
& C_{n+1}=\left\{x \in C_{n}:\left\|w_{n}-x\right\| \leq\left\|v_{n}-x\right\| \leq\left\|x_{n}-x\right\|\right\}, \\
& x_{n+1}=P_{C_{n+1}} x_{1} .
\end{aligned}
$$


Theorem 4.1 Let $C \subseteq H_{1}, Q \subseteq H_{2}, A, F, G, \mathcal{T}$ and $\mathcal{S}$ be as in Algorithm 4.1. Assume that the following set of control conditions are satisfied:

(C1) $\left\{\lambda_{n}\right\} \subset[a, b]$ for some $a, b \in\left(0, \min \left\{\frac{1}{2 c_{1}}, \frac{1}{2 c_{2}}\right\}\right)$;

(C2) $0 \leq d<e \leq \alpha_{n} \leq f<1, \liminf _{n \rightarrow \infty} r_{n}>0, \lim _{n \rightarrow 0} t_{n}=0=\lim _{n \rightarrow 0} s_{n}$;

(C3) $0<\xi<\frac{1}{\|A\|^{2}}$.

If $\Gamma \neq \emptyset$ then the sequences $\left\{x_{n}\right\},\left\{y_{n}\right\}$ and $\left\{z_{n}\right\}$ defined by Algorithm 4.1 converge strongly to a point in $\Gamma$.

Proof For simplicity, we divide the proof into the following four steps:

Step 1 . The set $C_{n}$ is nonempty closed and convex for all $n \geq 1$.

Note that, since

$$
\left\{x \in C_{n}:\left\|w_{n}-x\right\|^{2} \leq\left\|x_{n}-x\right\|^{2}\right\}=\left\{x \in C_{n}:\left\|w_{n}\right\|^{2}-\left\|x_{n}\right\|^{2} \leq 2\left\langle w_{n}-x_{n}, x\right\rangle\right\},
$$

the set $C_{n+1}$ is closed and convex.

Now for arbitrary $x^{*} \in \Gamma$, it follows from the estimate (10) that

$$
\left\|w_{n}-x^{*}\right\|^{2} \leq\left\|v_{n}-x^{*}\right\|^{2}-\xi\left(1-\xi\left\|A^{*}\right\|^{2}\right) \sigma_{n}^{2}-\xi\left\|u_{n}-A v_{n}\right\|^{2} .
$$

In view of condition (C3) and the estimates (3)-(5), we deduce from the above estimate that

$$
\left\|w_{n}-x^{*}\right\| \leq\left\|v_{n}-x^{*}\right\| \leq\left\|x_{n}-x^{*}\right\|
$$

The estimate (21) also establishes the fact that $\Gamma \subset C_{n+1}$ for all $n \geq 1$. In conclusion, Algorithm 4.1 is well-defined.

Step 2. The sequences $\left\{x_{n}\right\}$ and $\left\{w_{n}\right\}$ are bounded and $x_{n} \rightarrow p$ as $n \rightarrow \infty$.

For this, we proceed as follows.

Note that $x_{n+1}=P_{C_{n+1}} x_{1}$, therefore $\left\|x_{n+1}-x_{1}\right\| \leq\left\|x_{0}-x_{1}\right\|$ for all $x_{0} \in C_{n+1}$. In particular, we have $\left\|x_{n+1}-x_{1}\right\| \leq\left\|P_{\Gamma} x_{1}-x_{1}\right\|$. This implies that the sequence $\left\{x_{n}\right\}$ and consequently $\left\{w_{n}\right\}$ are bounded. Moreover $x_{n}=P_{C_{n}} x_{1}$ and $x_{n+1}=P_{C_{n+1}} x_{1} \in C_{n+1} \subset C_{n}$, we have

$$
\begin{aligned}
0 & \leq\left\langle x_{1}-x_{n}, x_{n}-x_{n+1}\right\rangle \\
& =\left\langle x_{1}-x_{n}, x_{n}-x_{1}+x_{1}-x_{n+1}\right\rangle \\
& \leq-\left\|x_{1}-x_{n 1}\right\|^{2}+\left\|x_{n+1}-x_{1}\right\|\left\|x_{n}-x_{1}\right\| .
\end{aligned}
$$

Simplifying the above estimate, we get $\left\|x_{n}-x_{1}\right\| \leq\left\|x_{n+1}-x_{1}\right\|$. Hence, the sequence $\left\{\| x_{n}-\right.$ $\left.x_{1} \|\right\}$ is nondecreasing and

$$
\lim _{n \rightarrow \infty}\left\|x_{n}-x_{1}\right\| \text { exists. }
$$

Note that

$$
\begin{aligned}
\left\|x_{n+1}-x_{n}\right\|^{2} & =\left\|x_{n+1}-x_{1}+x_{1}-x_{n}\right\|^{2} \\
& =\left\|x_{n+1}-x_{1}\right\|^{2}+\left\|x_{n}-x_{1}\right\|^{2}-2\left\langle x_{n}-x_{1}, x_{n+1}-x_{1}\right\rangle
\end{aligned}
$$




$$
\begin{aligned}
& =\left\|x_{n+1}-x_{1}\right\|^{2}+\left\|x_{n}-x_{1}\right\|^{2}-2\left\langle x_{n}-x_{1}, x_{n+1}-x_{n}+x_{n}-x_{1}\right\rangle \\
& =\left\|x_{n+1}-x_{1}\right\|^{2}-\left\|x_{n}-x_{1}\right\|^{2}-2\left\langle x_{n}-x_{1}, x_{n+1}-x_{n}\right\rangle \\
& \leq\left\|x_{n+1}-x_{1}\right\|^{2}-\left\|x_{n}-x_{1}\right\|^{2} .
\end{aligned}
$$

Taking limsup on both sides of the above estimate and utilizing (22), we have $\limsup _{n \rightarrow \infty}\left\|x_{n+1}-x_{n}\right\|^{2}=0$. That is,

$$
\lim _{n \rightarrow \infty}\left\|x_{n+1}-x_{n}\right\|=0
$$

Observe that

$$
\left\|x_{m}-x_{n}\right\| \leq\left\|x_{m}-x_{m-1}\right\|+\left\|x_{m-1}-x_{m-2}\right\|+\cdots+\left\|x_{n+1}-x_{n}\right\| .
$$

Utilizing (23), the above estimate implies that the sequence $\left\{x_{n}\right\}$ is Cauchy and hence $x_{n} \rightarrow$ $p$ as $n \rightarrow \infty$ for some $p \in C$.

Step 3. Show that $p \in \Gamma$ such that $z_{n} \rightarrow p$ as $n \rightarrow \infty$ and $u_{n} \rightarrow A p$ as $n \rightarrow \infty$.

In view of the definition of the set $C_{n+1}$, we have $\left\|w_{n}-x_{n+1}\right\| \leq\left\|v_{n}-x_{n+1}\right\| \leq\left\|x_{n}-x_{n+1}\right\|$. Therefore, we have the two observations

$$
\begin{aligned}
\left\|w_{n}-x_{n}\right\| & \leq\left\|w_{n}-x_{n+1}\right\|+\left\|x_{n+1}-x_{n}\right\| \\
& \leq 2\left\|x_{n+1}-x_{n}\right\|
\end{aligned}
$$

and

$$
\begin{aligned}
\left\|v_{n}-x_{n}\right\| & \leq\left\|v_{n}-x_{n+1}\right\|+\left\|x_{n+1}-x_{n}\right\| \\
& \leq 2\left\|x_{n+1}-x_{n}\right\| .
\end{aligned}
$$

Letting $n \rightarrow \infty$ and utilizing (23), we get

$$
\lim _{n \rightarrow \infty}\left\|w_{n}-x_{n}\right\|=0=\lim _{n \rightarrow \infty}\left\|v_{n}-x_{n}\right\|
$$

Since $\left\|w_{n}-x^{*}\right\|^{2} \leq\left\|x_{n}-x^{*}\right\|^{2}-\xi\left(1-\xi\left\|A^{*}\right\|^{2}\right) \sigma_{n}^{2}-\xi\left\|u_{n}-A v_{n}\right\|^{2}$, rearranging the terms we get

$$
\begin{aligned}
\xi\left(1-\xi\left\|A^{*}\right\|^{2}\right) \sigma_{n}^{2}+\xi\left\|u_{n}-A v_{n}\right\|^{2} & \leq\left\|x_{n}-x^{*}\right\|^{2}-\left\|w_{n}-x^{*}\right\|^{2} \\
& =\left(\left\|x_{n}-x^{*}\right\|+\left\|w_{n}-x^{*}\right\|\right)\left\|x_{n}-w_{n}\right\| .
\end{aligned}
$$

In view of condition (C3) and the estimate (24), we deduce from the above estimate that

$$
\begin{aligned}
\lim _{n \rightarrow \infty}\left\|\frac{1}{s_{n}} \int_{0}^{s_{n}} S(s) u_{n} d s-A v_{n}\right\| & =\lim _{n \rightarrow \infty}\left\|\frac{1}{t_{n}} \int_{0}^{t_{n}} T(t) z_{n} d t-z_{n}\right\| \\
& =\lim _{n \rightarrow \infty}\left\|u_{n}-A v_{n}\right\|=0 .
\end{aligned}
$$


Reasoning as above in Sect. 3, we have

$$
\lim _{n \rightarrow \infty}\left\|u_{n}-S(t) u_{n}\right\|=0=\lim _{n \rightarrow \infty}\left\|z_{n}-T(s) z_{n}\right\|
$$

Since $x_{n} \rightarrow p$ as $n \rightarrow \infty$, it follows from the estimates (17) and (20) that $z_{n} \rightarrow p$ and $v_{n} \rightarrow p$ as $n \rightarrow \infty$. Further, it follows from $v_{n} \rightarrow p$ as $n \rightarrow \infty$ and (25) that $u_{n} \rightarrow A p$ as $n \rightarrow \infty$. Now observe that

$$
\begin{aligned}
\|T(s) p-p\| & \leq\left\|T(s) p-T(s) z_{n}\right\|+\left\|T(s) z_{n}-z_{n}\right\|+\left\|z_{n}-p\right\| \\
& \leq 2\left\|z_{n}-p\right\|+\left\|T(s) z_{n}-z_{n}\right\| .
\end{aligned}
$$

Utilizing the fact that $z_{n} \rightarrow p$ as $n \rightarrow \infty$ together with the estimate (26), we conclude that $p \in \operatorname{Fix}(\mathcal{T})$. Similarly, from Lemma 3.1(i) we get $p \in \operatorname{EP}(C, F)$ and hence $p \in \operatorname{EP}(C, F) \cap$ $\operatorname{Fix}(\mathcal{T})$. Moreover, reasoning as above we can also prove that $A p \in \operatorname{EP}(Q, G) \cap \operatorname{Fix}(\mathcal{S})$ and hence $p \in \Gamma$. This completes the proof.

Corollary 4.1 ([18]) Let $C \subseteq H_{1}, Q \subseteq H_{2}, A, F$ and $G$ be as in Algorithm 4.1 and let $T$ and $S$ be two nonexpansive mappings. Assume that the following set of control conditions are satisfied:

(C1) $\left\{\lambda_{n}\right\} \subset[a, b]$ for some $a, b \in\left(0, \min \left\{\frac{1}{2 c_{1}}, \frac{1}{2 c_{2}}\right\}\right)$;

(C2) $0 \leq d<e \leq \alpha_{n} \leq f<1, \liminf _{n \rightarrow \infty} r_{n}>0$;

(C3) $0<\xi<\frac{1}{\|A\|^{2}}$.

If $\Gamma \neq \emptyset$ then the sequences $\left\{x_{n}\right\},\left\{y_{n}\right\}$ and $\left\{z_{n}\right\}$ defined by Algorithm 4.1 converge strongly to a point in $\Gamma$.

In order to solve the classical equilibrium problem together with the fixed point problem of nonexpansive semigroup, we prove the following result.

Theorem 4.2 Let $C \subseteq H_{1}, Q \subseteq H_{2}, A, F, G, \mathcal{T}$ and $\mathcal{S}$ be as in Algorithm 4.1. Assume that the following set of control conditions are satisfied:

(C1) $\left\{\lambda_{n}\right\} \subset[a, b]$ for some $a, b \in\left(0, \min \left\{\frac{1}{2 c_{1}}, \frac{1}{2 c_{2}}\right\}\right)$;

(C2) $0 \leq d<e \leq \alpha_{n} \leq f<1, \liminf _{n \rightarrow \infty} r_{n}>0, \lim _{n \rightarrow 0} t_{n}=0=\lim _{n \rightarrow 0} s_{n}$;

(C3) $0<\xi<\frac{1}{\|A\|^{2}}$.

If $\Gamma \neq \emptyset$ then the sequences $\left\{x_{n}\right\},\left\{y_{n}\right\}$ and $\left\{z_{n}\right\}$ defined by Algorithm 4.1 converge strongly to a point in $\Gamma$.

Proof Set $H_{1}=H_{2}, C=Q$ and $A=I$ (the identity mapping) then the desired result follows from Theorem 4.1 immediately.

Similarly, the following result addresses the classical equilibrium problem together with the fixed point problem of nonexpansive mappings.

Corollary 4.2 Let $C \subseteq H_{1}, Q \subseteq H_{2}, A, F$ and $G$ be as in Algorithm 4.1 and let $T$ and $S$ be two nonexpansive mappings. Assume that the following set of control conditions are satisfied:

(C1) $\left\{\lambda_{n}\right\} \subset[a, b]$ for some $a, b \in\left(0, \min \left\{\frac{1}{2 c_{1}}, \frac{1}{2 c_{2}}\right\}\right)$; 
(C2) $0 \leq d<e \leq \alpha_{n} \leq f<1, \liminf _{n \rightarrow \infty} r_{n}>0$;

(C3) $0<\xi<\frac{1}{\|A\|^{2}}$.

If $\Gamma \neq \emptyset$ then the sequences $\left\{x_{n}\right\},\left\{y_{n}\right\}$ and $\left\{z_{n}\right\}$ defined by Algorithm 4.1 converge strongly to a point in $\Gamma$.

\section{Numerical example}

This section is devoted to strengthening the result presented in Theorem 4.1 with the help of a numerical example. In order to examine the behavior of Algorithm 4.1, we study the extended version of the Nash-Cournot oligopolistic equilibrium model [16] to the split equilibrium model [22].

Example 5.1 Let $H_{1}=\mathbb{R}^{n}$ and $H_{2}=\mathbb{R}, C=[-5,5]^{n}$ and $Q=[-1, \infty)$. The bifunction $F$ : $C \times C \rightarrow \mathbb{R}$ is defined as

$$
F(x, y)=\langle M x+N y+p, y-x\rangle \quad \text { for all } x, y \in C,
$$

where $p \in \mathbb{R}^{n}, M_{n \times n}, N_{n \times n}$ are symmetric positive semidefinite and $N-M$ is negative semidefinite. Note that the matrices $M$ and $N$ are generated randomly so as to satisfy assumptions (B1)-(B5) with the Lipschitz-type constants $c_{1}=c_{2}=\frac{1}{2}\|N-M\|$. Moreover, the matrices $M$ and $N-M$ are of the form $D^{T} D$ with $D_{n \times n}$ being randomly generated in the interval $[-5,5]$. The bounded linear operator $A: \mathbb{R}^{n} \rightarrow \mathbb{R}$ is defined by $A x=\langle a, x\rangle$ where $a \in \mathbb{R}^{n}$ whose entries are generated randomly (and uniformly) in $[1, n]$. Moreover, $A^{*} y=y \cdot a$ and $\|A\|=\|a\|$. The bifunction $G: Q \times Q \rightarrow \mathbb{R}$ is defined as $u(v-u)$ for all $u, v \in$ $Q$. It is easy to check that $F$ and $G$ satisfy all conditions in Theorem 4.1. The nonexpansive semigroups $\mathcal{T}$ and $\mathcal{S}$ are defined as $T(t) x=\frac{1}{10^{t}} x$ for all $x \in C$ and $S(s) y=e^{-s} y$ for all $y \in Q$ with $0 \leq t, s<+\infty$. Choose $x_{0}=(1,1, \ldots, 1) \in \mathbb{R}^{n}$ as an initial guess with control parameters $\alpha_{n}=\frac{n}{100 n+1}, r_{n}=1, \lambda_{n}=\lambda=\frac{1}{4 c_{1}}$ and $\xi=\frac{1}{2\|a\|^{2}}$. Observe that computing the sequence $y_{n}$ in Algorithm 4.1, we need to solve the following optimization problem:

$$
\arg \min \left\{\lambda_{n} F\left(x_{n}, y\right)+\frac{1}{2}\left\|y-x_{n}\right\|^{2}: y \in C\right\}
$$

which is equivalent to the following convex quadratic problem:

$$
\arg \min \left\{\frac{1}{2} y^{T} H y+b^{T} y: y \in C\right\}
$$

where $H=2 \lambda N+I$ and $b=\lambda\left(M x_{n}-N x_{n}+p\right)-x_{n}$.

Similarly, for sequence $z_{n}$ in Algorithm 4.1, we solve the following problem:

$$
\arg \min \left\{\frac{1}{2} y^{T} \widetilde{H} y+\widetilde{b}^{T} y: y \in C\right\} \text {, }
$$

where $\widetilde{H}=H$ and $\widetilde{b}=\lambda\left(M y_{n}-N y_{n}+p\right)-x_{n}$.

On the other hand, the sequence $w_{n}$ in Algorithm 4.1, that is,

$$
w_{n}=P_{C}\left(v_{n}+\xi A^{*}\left(\frac{1}{s_{n}} \int_{0}^{s_{n}} S(s) u_{n} d s-A v_{n}\right)\right)=P_{C}\left(v_{n}+\xi\left(u_{n}-A v_{n}\right) a\right),
$$


implies the following distance optimization program:

$$
\arg \min \left\{\left\|v_{n}+\xi\left(u_{n}-A v_{n}\right) a-y\right\|^{2}: y \in C\right\},
$$

which is equivalent to the following problem:

$$
\arg \min \left\{\frac{1}{2} y^{T} y+b^{T} y: y \in C\right\}
$$

where $b=-v_{n}-\xi\left(u_{n}-A v_{n}\right) a$.

The stopping criterion for the sequence is defined as $\left\|x_{n+1}-x_{n}\right\| \leq T O L$. The numerical results for Algorithm 4.1 with different tolerances $D_{n}$ are shown in Table 1 along with the time of execution in second ( $\mathrm{CPU}(\mathrm{Sec}))$ and the number of iterations (Iter.). Moreover, Figs. 1-2 depict the convergence of Algorithm 4.1 under different tolerance levels. The experiments are performed on a PC Desktop Intel(R) Core(TM) i3-3217U CPU @ $1.80 \mathrm{GHz}$ $1.80 \mathrm{Ghz}$, RAM 4.00 GB with Matlab version R2013a.

Table 1 Numerical results for Algorithm 4.1

\begin{tabular}{rlrr}
\hline$n$ & TOL $D_{n}$ & CPU (Sec) & ITER. \\
\hline 1 & $10^{-3}$ & 0.406641 & 8 \\
& $10^{-6}$ & 16.270539 & 257 \\
5 & $10^{-3}$ & 0.506633 & 10 \\
& $10^{-6}$ & 17.740290 & 268 \\
10 & $10^{-3}$ & 0.758019 & 15 \\
& $10^{-6}$ & 18.695281 & 286 \\
100 & $10^{-3}$ & 0.893022 & 17 \\
& $10^{-6}$ & 15.779898 & 250 \\
500 & $10^{-3}$ & 0.922178 & 18 \\
& $10^{-6}$ & 14.680938 & 237 \\
\hline
\end{tabular}

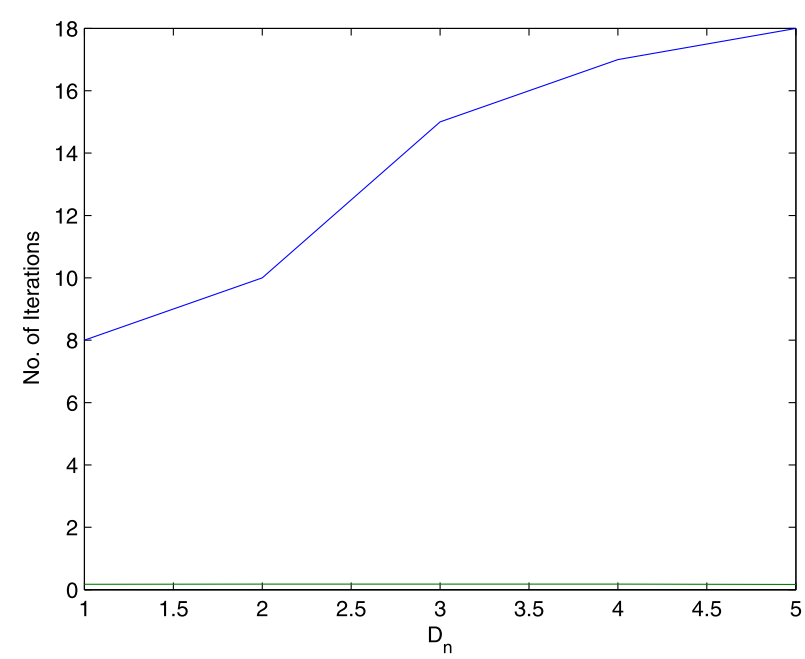

Figure 1 Comparison with tolerance of $10^{-3}$ 


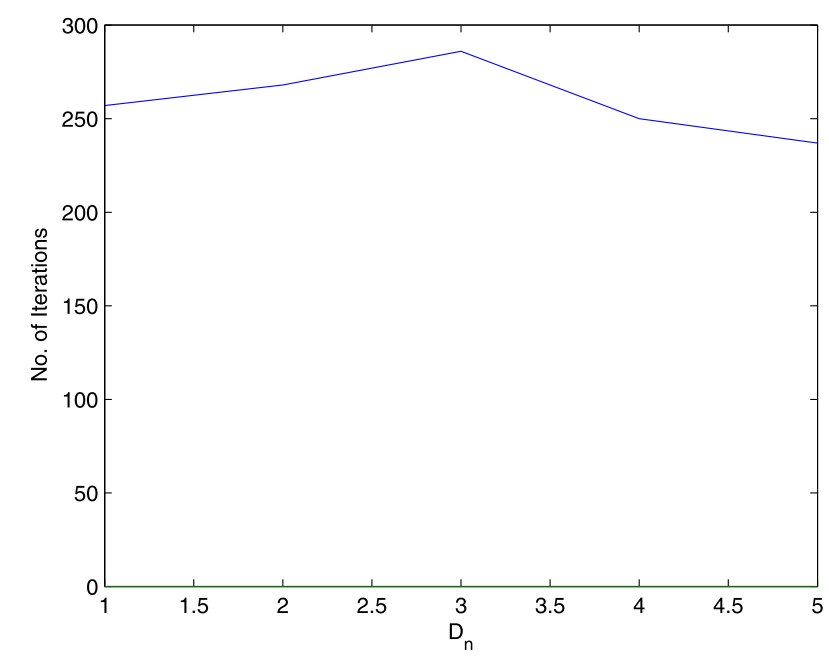

Figure 2 Comparison with tolerance of $10^{-6}$

\section{Conclusion}

We have proposed a modified version of the extragradient algorithm and computed a common solution to the split equilibrium problem and the fixed point problem of nonexpansive semigroup. The convergence analysis of the proposed algorithm has been established under a suitable set of control conditions. Moreover, theoretical results have been implemented via a numerical example to a generalized form of the Nash-Cournot equilibrium model.

\section{Acknowledgements}

The authors wish to thank the anonymous reviewers and the handling editor of the journal for careful reading and valuable suggestions to improve the quality of the paper.

\section{Funding}

This project was supported by Theoretical and Computational Science (TaCS-CoE), Faculty of Science, KMUTT. The author Yasir Arfat was supported by the Petchra Pra Jom Klao Ph.D. Research Scholarship from King Mongkut's University of Technology Thonburi, Thailand(Grant No.16/2562).

\section{Availability of data and materials}

Data sharing not applicable to this article as no datasets were generated or analysed during the current study.

\section{Competing interests}

The authors declare that they have no competing interests.

\section{Authors' contributions}

All authors contributed equally and significantly in writing this article. All authors read and approved the final manuscript.

\section{Author details}

'KMUTTFixed Point Research Laboratory, KMUTT-Fixed Point Theory and Applications Research Group, Department of Mathematics, Faculity of Science, King Mongkut's University of Technology Thonburi (KMUTT), 126 Pracha-Uthit Road, Bang Mod, Thrung Khru, 10140, Bangkok, Thailand. ${ }^{2}$ Center of Excellence in Theoretical and Computational Science (TaCS-CoE), Science Laboratory Building, King Mongkut's University of Technology Thonburi (KMUTT), 126 Pracha-Uthit Road,Band Mod,Thrung Khru, 10140 Bangkok, Thailand. ${ }^{3}$ Department of Medical Research, China Medical University Hospital, China Medical University, 40402 Taichung, Taiwan. ${ }^{4}$ Department of Mathematics, Faculty of Science, King Mongkut's University of Technology Thonburi (KMUTT), 126 Pracha-Uthit Road,Band Mod, Thrung Khru, 10140 Bangkok, Thailand. ${ }^{5}$ Department of Mathematics, COMSATS University Islamabad, Lahore Campus, 54000, Lahore, Pakistan. ${ }^{6}$ Department of Mathematics, The Islamia University of Bahawalpur, Baghdad Campus, Bahawalpur 63100, Pakistan.

\section{Publisher's Note}

Springer Nature remains neutral with regard to jurisdictional claims in published maps and institutional affiliations. 
Received: 10 February 2020 Accepted: 8 September 2020 Published online: 22 September 2020

\section{References}

1. Adler, R., Dedieu, J.P., Margulies, J.Y., Martens, M., Shub, M.: Newton's method on Riemannian manifolds and a geometric model for human spine. IMA J. Numer. Anal. 22, 359-390 (2002)

2. Aleyner, A., Censor, Y.: Best approximation to common fixed points of a semigroup of nonexpansive operators. J. Nonlinear Convex Anal. 6(1), 137-151 (2005)

3. Anh, P.N.: A hybrid extragradient method extended to fixed point problems and equilibrium problems. Optimization 62(2), 271-283 (2013)

4. Aubin, J.P.: Optima and Equilibria: An Introduction to Nonlinear Analysis. Springer, New York (1998)

5. Barbu, V.: Nonlinear Semigroups and Differential Equations in Banach Spaces. Noordhoff, Leyden (1976)

6. Blum, E., Oettli, W.: From optimization and variational inequalities to equilibrium problems. Math. Stud. 63, 123-145 (1994)

7. Brezis, H., Pazy, A.: Semigroups of nonlinear contractions on convex sets. J. Funct. Anal. 6, $237-281$ (1970)

8. Byrne, C.: Iterative oblique projection onto convex sets and the split feasibility problem. Inverse Probl. 18, 441-453 (2002)

9. Censor, Y., Bortfeld, T., Martin, B., Trofimov, A.: A unified approach for inversion problems in intensity modulated radiation therapy. Phys. Med. Biol. 51, 2353-2365 (2006)

10. Censor, Y., Elfving, T., Kopf, N., Bortfeld, T.: The multiple-sets split feasibility problem and its applications for inverse problems. Inverse Probl. 21, 2071-2084 (2005)

11. Censor, Y., Gibali, A., Reich, S.: The subgradient extragradient method for solving variational inequalities in Hilbert space. J. Optim. Theory Appl. 148, 318-335 (2011)

12. Censor, Y., Gibali, A., Reich, S.: Algorithms for the split variational inequality problem. Numer. Algorithms 59, 301-323 (2012)

13. Cianciaruso, F., Marino, G., Muglia, L.: Iterative methods for equilibrium and fixed point problems for nonexpansive semigroups in Hilbert spaces. J. Optim. Theory Appl. 146, 491-509 (2010)

14. Combettes, P.L.: The convex feasibility problem in image recovery. Adv. Imaging Electron Phys. 95, 155-453 (1996)

15. Combettes, P.L., Hirstoaga, S.A.: Equilibrium programming in Hilbert spaces. J. Nonlinear Convex Anal. 6, 117-136 (2005)

16. Contreras, J., Klusch, M., Krawczyk, J.B.: Numerical solution to Nash-Cournot equilibria in coupled constraint electricity markets. IEEE Trans. Power Syst. 19, 195-206 (2004)

17. Daniele, P., Giannessi, F., Maugeri, A.: Equilibrium Problems and Variational Models, Kluwer Academic, Boston (2003)

18. Dinh, B.V., Son, D.X., Anh, T.V.: Extragradient-proximal methods for split equilibrium and fixed point problems in Hilbert spaces. Vietnam J. Math. 45, 651-668 (2017)

19. Harisa, S.A., Khan, M.A.A., Mumtaz, F., Farid, N., Morsy, A., Nisar, K.S., Ghaffar, A.: Shrinking Cesaro means method for the split equilibrium and fixed point problems in Hilbert spaces. Adv. Differ. Equ. 2020, 345 (2020)

20. He, Z.: The split equilibrium problem and its convergence algorithms. J. Inequal. Appl. 2012, 162 (2012)

21. Hieu, D.V.: Parallel extragradient-proximal methods for split equilibrium problems. Math. Model. Anal. 21, 478-501 (2016)

22. Hieu, D.V.: Two hybrid algorithms for solving split equilibrium problems. Int. J. Comput. Math. 95, 561-583 (2018)

23. Kazmi, K.R., Rizvi, S.H.: Iterative approximation of a common solution of a split equilibrium problem, a variational inequality problem and a fixed point problem. J. Egypt. Math. Soc. 21, 44-51 (2013)

24. Kazmi, K.R., Rizvi, S.H.: Implicit iterative method for approximating a common solution of split equilibrium problem and fixed point problem for a nonexpansive semigroup. Arab J. Math. Sci. 20, 57-75 (2014)

25. Khan, M.A.A.: Convergence characteristics of a shrinking projection algorithm in the sense of Mosco for split equilibrium problem and fixed point problem in Hilbert spaces. Linear Nonlinear Anal. 3, 423-435 (2017)

26. Khan, M.A.A., Arfat, Y., Butt, A.R.: A shrinking projection approach to solve split equilibrium problems and fixed point problems in Hilbert spaces. UPB Sci. Bull., Ser. A 80(1), 33-46 (2018)

27. Korpelevich, G.M.: Extragradient method for finding saddle points and other problems. Matecon 12, $747-756$ (1976)

28. Lau, A.T., Shioji, N., Takahashi, W.: Existence of nonexpansive retractions for amenable semigroups of nonexpansive mappings and nonlinear ergodic theorems in Banach spaces. J. Funct. Anal. 161, 62-75 (1999)

29. Li, J.: Split equilibrium problems for related games and applications to economic theory. Int. Game Theory Rev. 20, 1850005 (2018)

30. Martinet, B.: Regularization dinequation variationelles per approximation successive. Rev. Fr. Inform. Rech. Oper. 4, 154-158 (1970)

31. Moudafi, A.: Proximal point algorithm extended to equilibrium problem. J. Nat. Geom. 15, 91-100 (1999)

32. Moudafi, A.: Split monotone variational inclusions. J. Optim. Theory Appl. 150, 275-283 (2011)

33. Nadezhkina, N., Takahashi, W.: Strong convergence theorem by a hybrid method for nonexpansive mappings and Lipschitz continuous monotone mappings. SIAM J. Optim. 16(4), 1230-1241 (2006)

34. Plubtieng, S., Punpaeng, R.: Fixed point solutions of variational inequalities for nonexpansive semigroups in Hilbert spaces. Math. Comput. Model. 48, 279-286 (2008)

35. Rockafellar, R.T.: Monotone operators and the proximal point algorithm. SIAM J. Control Optim. 14, $877-898$ (1976)

36. Rode, G.: An ergodic theorem for semigroups of nonexpansive mappings in a Hilbert space. J. Math. Anal. Appl. 85 , 172-178 (1982)

37. Saelee, S., Kumam, P., Moreno, J.M.: Simultaneous iterative methods of asymptotically quasi-nonexpansive semigroups for split equality common fixed point problem in Banach spaces. Math. Methods Appl. Sci. 42(17), 5794-5804 (2019)

38. Shimizu, T., Takahashi, W.: Strong convergence to common fixed points of families of nonexpansive mappings. J. Math. Anal. Appl. 211, 71-83 (1997)

39. Song, Y., Xu, S.: Strong convergence theorems for nonexpansive semigroup in Banach spaces. J. Math. Anal. Appl. 338, 152-161 (2008)

40. Suzuki, T:: On strong convergence to common fixed points of nonexpansive semigroup in Hilbert spaces. Proc. Am. Math. Soc. 131, 2133-2136 (2002) 
41. Thuy, N.T.T: An iterative method for equilibrium, variational inequality, and fixed point problems for a nonexpansive semigroup in Hilbert spaces. Bull. Malays. Math. Sci. Soc. 38(1), 113-130 (2015)

42. Udriste, C.: Convex Functions and Optimization Methods on Riemannian Manifolds. Mathematics and Its Applications, vol. 297. Kluwer Academic, Dordrecht (1994)

43. Wang, S., Gong, X., Kang, S.M.: Strong convergence theorem on split equilibrium and fixed point problems in Hilbert spaces. Bull. Malays. Math. Sci. Soc. 41, 1309-1326 (2018)

Submit your manuscript to a SpringerOpen ${ }^{\circ}$ journal and benefit from:

- Convenient online submission

$\checkmark$ Rigorous peer review

Open access: articles freely available online

- High visibility within the field

- Retaining the copyright to your article

Submit your next manuscript at $\gg$ springeropen.com 